\title{
Time series analysis of physiologic left ventricular reconstruction in ischemic cardiomyopathy
}

\author{
Marco Cirillo, MD, ${ }^{\mathrm{a}}$ Marco Campana, MD, ${ }^{\mathrm{b}}$ Federico Brunelli, MD, ${ }^{\mathrm{c}}$ Margherita Dalla Tomba, MD, \\ Zean Mhagna, MD, ${ }^{\mathrm{c}}$ Antonio Messina, MD, ${ }^{\mathrm{c}}$ Emmanuel Villa, $\mathrm{MD},{ }^{\mathrm{c}}$ Giuseppe Natalini, MD, ${ }^{\mathrm{d}}$ and \\ Giovanni Troise, $\mathrm{MD}^{\mathrm{c}}$
}

\begin{abstract}
Objective: The history of left ventricular reconstruction has demonstrated that the full spectrum of recoverable physiologic parameters is essential for a good functional result. We report the long-term outcome of a new surgical technique that arranges myocardial fibers in a near-normal disposition, also recovering left ventricular twisting.

Methods: Between May 2006 and October 2013, 29 consecutive patients with previous anterior myocardial infarction and heart failure symptoms underwent physiologic left ventricular reconstruction surgery and coronary revascularization. Patients were examined by means of standard echocardiography and 2-dimensional speckle tracking at 8 time steps until 7 years after surgery. Ten geometric and functional parameters were evaluated at each step and analyzed by the linear mixed model test.
\end{abstract}

Results: Hospital mortality was $0 \%$. The mean percentage of indexed enddiastolic and end-systolic volume reduction was $45.7 \%$ and $50.9 \%$, respectively. Ejection fraction and all of the volumes were significantly different in the postoperative period with a steady correction during time. Diastolic parameters were not worsened by surgical reconstruction. Ejection fraction and deceleration time showed a significant improvement during time. Left ventricular torsion increased immediately after the surgical correction from $2.8 \pm 4.4$ degrees to $8.7 \pm 3.9$ degrees $(P=.02)$ and was still present 4 years after surgery.

Conclusions: Surgical conduction of ventricular reconstruction should be standardized to achieve the full spectrum of recoverable physiologic parameters. The renewal of ventricular torsion should be pursued as an adjunctive element of ventricular efficiency, mainly in ventricles that work at a critical level in the Frank-Starling relationship and pressure-volume loop. (J Thorac Cardiovasc Surg 2016;152:382-91)

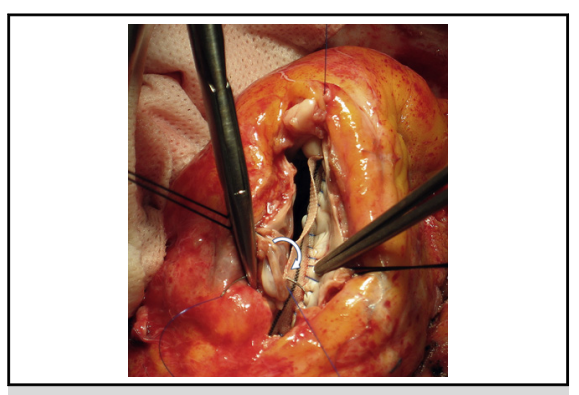

Physiologic reconstruction of the LV with respect to the orientation of the fibers.

\section{Central Message}

Surgically induced renewal of twisting helps remodeling in reconstructed ischemic ventricles working with critical mechanics.

\section{Perspective}

Surgical LV reconstruction should make all recoverable physiologic parameters effective. The renewal of ventricular torsion could be an adjunctive element of ventricular efficiency, mainly in ventricles working with critical mechanics. Further studies should include highresolution speckle-tracking analysis to infer a more precise surgical planning for the arrangement of fibers.

See Editorial Commentary page 392.
The history of left ventricular (LV) reconstruction, from the first successful open excision ${ }^{1}$ to the Surgical Treatment for Ischemic Heart Failure (STICH) trial, ${ }^{2}$ has clearly demonstrated that significant volume reduction is essential to obtain

\footnotetext{
From the ${ }^{\mathrm{a}}$ Heart Failure Surgery Unit, Poliambulanza Foundation Hospital; ${ }^{\mathrm{b}}$ Echocardiography Laboratory, Cardiology Unit, Cardiovascular Department, Poliambulanza Foundation Hospital; ${ }^{\mathrm{c}}$ Cardiac Surgery Unit, Cardiovascular Department, Poliambulanza Foundation Hospital; and ${ }^{\mathrm{d} I n t e n s i v e ~ C a r e ~ U n i t, ~}$ Emergency Department, Poliambulanza Foundation Hospital, Brescia, Italy.

Received for publication Dec 5, 2015; revisions received March 14, 2016; accepted for publication March 17, 2016; available ahead of print May 7, 2016.

Address for reprints: Marco Cirillo, MD, Poliambulanza Foundation Hospital, Via Leonida Bissolati 57, 25125 Brescia, Italy (E-mail: marco.cirillo@poliambulanza.it). 0022-5223/\$36.00

Copyright (c) 2016 by The American Association for Thoracic Surgery

http://dx.doi.org/10.1016/j.jtcvs.2016.03.087
}

a good functional result, but it is not the only parameter to rely on. From endoventricular circular patch plasty ${ }^{3}$ up to date, several studies have shown ${ }^{4-8}$ that LV shape and geometry have at least an equivalent value to restore cardiac function and obtain steady clinical results. The role of myocardial fibers' orientation and their direct functional expression, LV torsion, recently have gained attention and interest both in normal hearts and in pathologic conditions, including

Scanning this QR code will take you the videos for the article. 


\section{Abbreviations and Acronyms \\ DT = deceleration time \\ EDVi = end-diastolic volume index \\ $\mathrm{EF} \quad=$ ejection fraction \\ $\mathrm{ESVi}=$ end-systolic volume index \\ $\mathrm{LV} \quad=$ left ventricle, left ventricular \\ MAPSE $=$ mitral annular plane systolic excursion \\ STICH $=$ Surgical Treatment for Ischemic Heart Failure \\ $2 \mathrm{D} \quad=2$-dimensional}

ischemic cardiomyopathy. ${ }^{9-14}$ Torsion is the functional expression of the normal 3-dimensional architecture of the LV wall. The shortening of obliquely oriented fiber bundles obtains the opposite twisting of the apex and the base of the ventricle, squeezing the ventricular chamber in highefficiency, energy-sparing mechanics. ${ }^{15}$ This movement is lost when the 3-dimensional structure is altered, as in ischemic cardiomyopathy. The unexpected potential to restore ventricular torsion after surgical treatment for ischemic cardiomyopathy was demonstrated in some clinical reports. ${ }^{16,17}$ According to this concept, we recently devised a new technique of $\mathrm{LV}$ reconstruction aimed at redirecting myocardial fibers to an almost normal setting. ${ }^{18,19}$ Renewal of LV torsion, as expression of restored fibers' orientation and good global ventricular function and efficiency, could contribute to achieve systolic contraction and diastolic relaxation with a lower energy consumption, ${ }^{20,21}$ mimicking its role in normal hearts. We report the long-term results of this new surgical approach with serial echocardiographic assessments over a 7-year follow-up period with the aim of demonstrating the time course of postoperative remodeling in these cases.

\section{PATIENTS AND METHODS \\ Patients}

Between May 2006 and October 2013, 29 consecutive patients with previous anterior myocardial infarction, ischemic cardiomyopathy, dominant anterior akinesia/dyskinesia, and prevalent heart failure symptoms underwent LV restoration surgery and coronary revascularization. The mean age of patients was $64 \pm 10$ years, and 10 patients were female. Mitral regurgitation was absent in 27 patients and mild in 2 patients. Eight patients who underwent operation in the same period but who required combined mitral surgery have been excluded from the analysis to have good basal residual function and the possibility to study diastolic parameters. The time interval from myocardial infarction was $71 \pm 74$ months (range, 6-274 months). The mean apical rotation was $0.8 \pm 4.4$ degrees, and LV
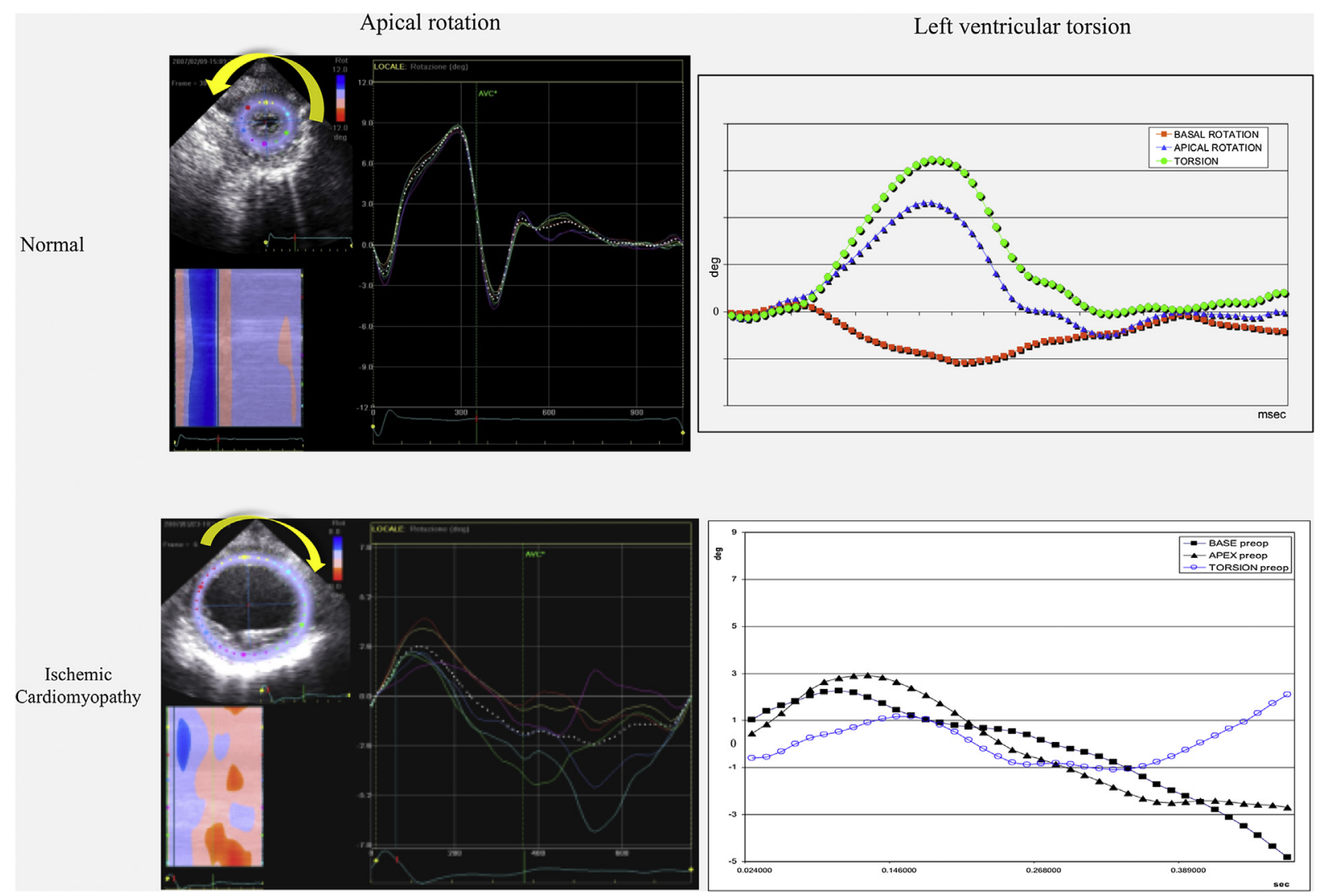

FIGURE 1. Comparison between apical rotation and LV torsion in normalcy and ischemic cardiomyopathy. In normalcy, apical rotation (counterclockwise) is opposite to the base (clockwise), all myocardial walls move synchronously, and the result is LV torsion. After anterior myocardial infarction and the loss of arrangement of fibers, apical rotation is consensual to the base (clockwise), and this nullifies LV torsion. 


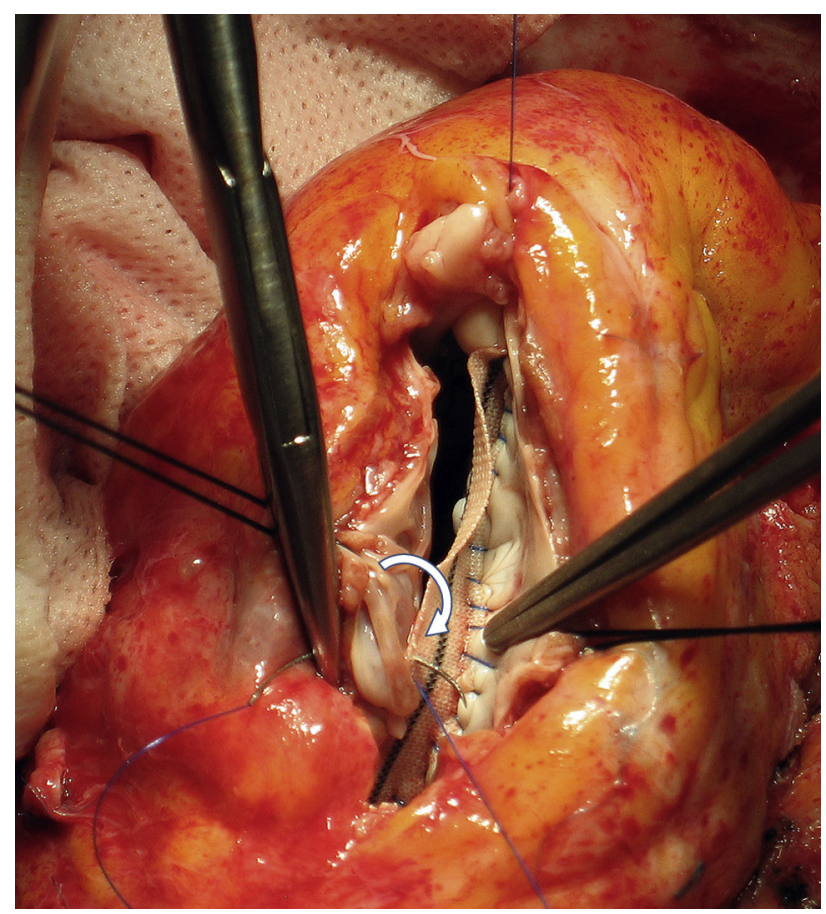

FIGURE 2. Surgical view showing the effect of the lateral suture on the myocardium with the aim of redirecting gross myocardial bundles of fibers in a more physiologic orientation.

torsion was $2.8 \pm 4.4$ degrees, preoperatively. Medical treatment did not differ from current guidelines in the choice of drugs and dosage.

\section{Methods}

Serial echocardiographic measurements. Patients were examined by means of standard echocardiography and 2-dimensional (2D) speckle-tracking analysis at 8 steps: Preoperatively (within 1 week before surgery), in the immediate postoperative period (within 1 week after

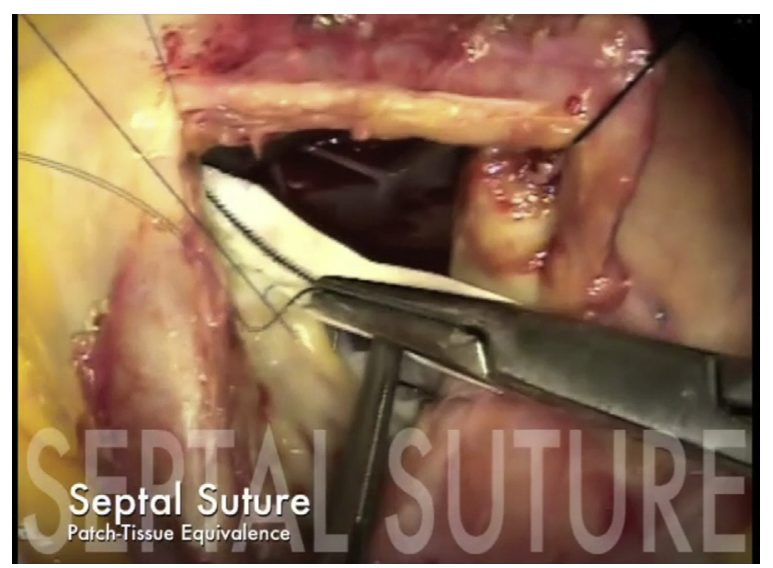

VIDEO 1. Surgical technique. Sequence of the described surgical technique showing the core steps: (1) Septal suture, (2) tailoring of the patch with arrow-shaped end to rebuild apex, and (3) shrinking lateral suture to reset orientation of fiber bundles. An example of LV torsion renewal in the operating room is included. Video available at http://www.jtcvsonline.org/article/S0022-5223(16)30110-6/addons. surgery), and at least 4 months, 8 months, 1 year, 2 years, 4 years, and 7 years after the operation. Ten LV geometric and functional parameters were considered at each step to represent both systolic and diastolic function: Absolute end-diastolic and end-systolic volumes, end-diastolic volume index (EDVi), and end-systolic volume index (ESVi); Simpson's biplane ejection fraction (EF); mitral E-wave deceleration time (DT); E/A ratio; mitral annular plane systolic excursion (MAPSE) at the lateral wall $^{22}$; and 2D speckle-tracking apical rotation and LV torsion. Apical rotation and LV torsion were calculated at only 3 steps, preoperatively, postoperatively, and at a mean follow-up interval of 3.8 years (22 patients).

All echocardiographic studies were performed by the same echocardiography laboratory, according to a standard, complete, dedicated study protocol, using a Vivid 7 or Vivid 9 ultrasound system (GE Healthcare, Buckinghamshire, UK). EchoPac PC Dimension (software version 6.1.2; GE Healthcare) was used for offline analysis, carried out by the same operator. Definitions and standardization of parameters followed the specific guidelines of the American Society of Echocardiography. ${ }^{23,24}$

LV torsion was assessed by 2D speckle-tracking echocardiography (Figure 1). Apical and basal short-axis planes were scanned at a high frame rate (at least 80 frames/sec) and stored for subsequent analysis. Criteria for proper short-axis views were mitral valve visibility at the basal level and no papillary muscle visibility at the apical level. The most circular views were considered for the speckle-tracking analysis. Torsion was calculated as the net difference in rotation between base and apex (systolic peak value, degrees).

Statistics. The linear mixed model test for repeated measures was used to compare preoperative and postoperative data, with preoperative values and time (categoric variable) as covariates in the regression model. Polynomial cubic (third degree) regression fitting curves with $R^{2}$ value ${ }^{25}$ was used to describe the time trend of echocardiographic measures. Linear correlation between apical rotation and LV torsion was calculated to confirm their interdependence. A box-and-whisker plot was used to highlight the value of postoperative surgical indexed volume reduction. The software used for statistical analysis and graphical output was IBM SPSS Statistics version 23 (New York, NY) and R version 3.2.3.

Surgical details. All of the operations were performed by means of a median sternotomy using a mild hypothermic $\left(33^{\circ} \mathrm{C}\right)$ cardiopulmonary bypass, aortic crossclamping, intermittent cold blood cardioplegia, and warm reperfusate.

Left ventriculotomy was performed laterally and parallel to the course of the left anterior descending artery. The LV restoration surgical technique was a strip-shaped patch endoventricular plasty according to the technique previously described. ${ }^{19}$ Peculiarities of this reconstruction are (1) the absence of a Fontan purse-string; (2) the shape of the patch (short minor axis compared with currently used circular or oval-shaped patches); (3) a tailored major axis of the patch adjusted to the length of normal ventricle; (4) an arrow-shaped end of the patch to rebuild ventricular apex; and (5) the asymmetric way of suturing the patch inside the ventricle.

The septal side of the patch is approximately equivalent to the length of the inferior septal rim; therefore, this suture is linear and starts a few centimeters near the aortic valve to exclude the septum and rebuild an elliptical chamber. ${ }^{26}$ The lateral side of the patch is shorter than the anterolateral side of the ventricle; therefore, the suture must adapt the ventricular border to the patch, shrinking the residual myocardium and resulting in a pleated suture. The aim of this asymmetric suture is to redirect (Figure 2) gross myocardial bundles of fibers in a more physiologic orientation (obliquely directed toward the right ventricle), compensating their displacement due to previous necrosis (Video 1). This theory was based on the evidence that transmural courses of fibers' orientation angles near infarct zones were similar to those of normal myocardium ${ }^{27}$ and on anatomic maps of myocardial fibers' disposition, common to all mammals. ${ }^{28}$ 


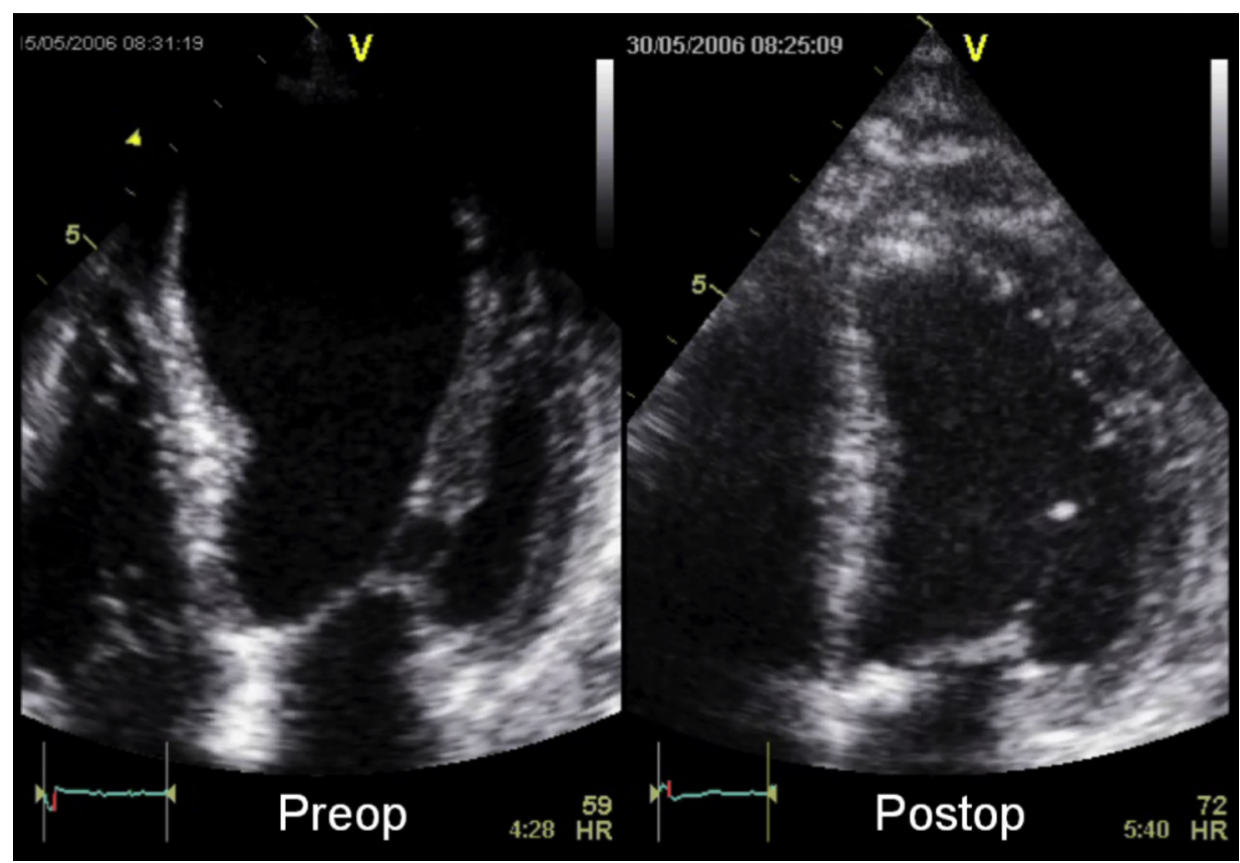

FIGURE 3. Echocardiographic comparison between preoperative and postoperative LV chamber showing the near-normal elliptical shape and dimensions obtained, the restored new apex, and the reduction in mitral valve tenting obtained only by the physiologic reconstruction of the ventricular chamber.

The patch used was Hemashield Platinum Finesse Ultra-thin Knitted Dacron Patch (Maquet Cardiovascular, Getinge Group, Wayne, NJ). The actual dimensions of the patch are $0.8 \times 7.6 \mathrm{~cm}$. The patch was tailored only in its major axis according to the estimated length of the normal ventricle of each patient (LV apex contiguous to the right ventricle apex). The final mean dimensions were $5.7 \pm 0.6 \mathrm{~cm}$ (range, $4-7 \mathrm{~cm}$ ). In all cases, the ventriculotomy was closed by overlapping the free edges in a

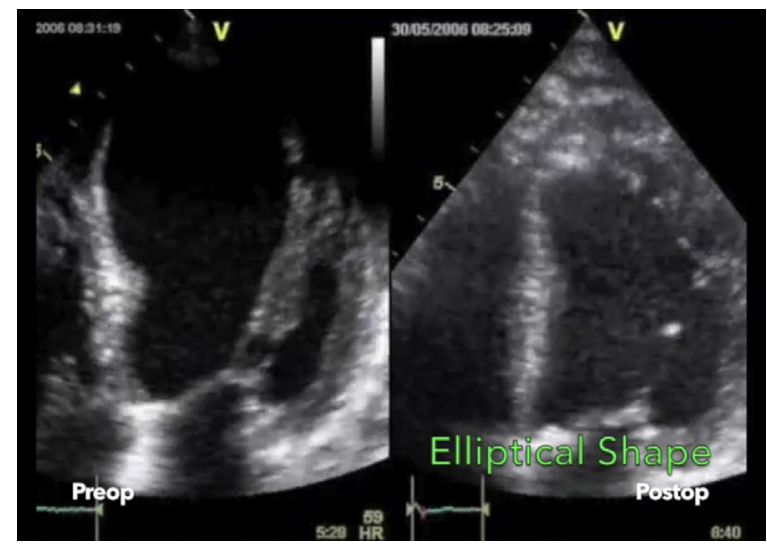

VIDEO 2. Echocardiographic study. Preoperative and postoperative echocardiographic standard and 2D speckle-tracking study in a 73-yearold female patient. Standard echocardiogram shows key modifications obtained by the described technique: Elliptical shape, small volume, new apex, and reduction in tenting of the mitral valve due to the restoration of a near-normal ventricular chamber. A 2D speckle-tracking echocardiogram shows the preoperative abnormal clockwise rotation of the dilated apex with fibers disarranged and the postoperative near-normal counterclockwise rotation of the restored new apex with reoriented fibers. Video available at http://www.jtcvsonline.org/article/S0022-5223(16)30110-6/ addons. "vest-over-pants" closure to occlude the excluded chamber. All patients received coronary artery bypass grafting to ensure complete revascularization. The left anterior descending artery was revascularized in all cases.

\section{RESULTS}

\section{Overall Clinical Data}

Hospital mortality was $0 \%$. Five patients died during follow-up, 1 of cardiac-related cause (myocardial infarction at 7.9 years); 3 of neoplasia at 1.4, 3.4, and 7.3 years; and 1 of cerebrovascular cause at 2.9 years. No new significant onset of mitral regurgitation or worsening of preoperative grade was found in the postoperative period.

\section{Echocardiographic Data}

An example of near-normal elliptical chamber and the renewal of global function obtained by means of the described technique is shown in Figure 3 and Video 2. In all patients, end-diastolic volume, EDVi, end-systolic volume, ESVi, and EF were significantly different in the postoperative period when compared with the preoperative values (Table 1). This difference was consistent during time, and there were no significant differences among postoperative serial measurements in regard to volumes, whereas EF significantly increased at 1 year $(P$ time $=.03$ and post hoc $P=.04$ at 1 year) (Tables 1 and 2; Figure 4, $A$ and $B)$. Diastolic parameters did not differ significantly from preoperative values (E/A, $P=.55$ and $\mathrm{DT}, P=.51$ ). The E/A ratio did not differ during time $(P$ time $=.15)$, whereas DT showed a progressive increase during time $(P$ time $=.001)$, with post hoc significant values at 4 months, 
TABLE 1. Echocardiographic systolic and diastolic parameters measured at 8 episodes

\begin{tabular}{|c|c|c|c|c|c|c|c|c|c|c|}
\hline & \multicolumn{8}{|c|}{ Echocardiographic controls } & \multicolumn{2}{|l|}{$P$ value } \\
\hline & Preoperative (29) & Postoperative (29) & 4 mo (29) & 8 mo (29) & 1 y (29) & $2 y(21)$ & $4 y(14)$ & 7 y (9) & Preoperative & Time \\
\hline EDV & $191 \pm 67$ & $107 \pm 32$ & $116 \pm 40$ & $123 \pm 49$ & $132 \pm 44$ & $118 \pm 45$ & $114 \pm 46$ & $109 \pm 34$ & .001 & .59 \\
\hline EDVi & $108 \pm 38$ & $61 \pm 18$ & $64 \pm 21$ & $65 \pm 21$ & $73 \pm 23$ & $65 \pm 20$ & $65 \pm 22$ & $64 \pm 21$ & .005 & .59 \\
\hline ESV & $137 \pm 62$ & $67 \pm 26$ & $72 \pm 28$ & $77 \pm 38$ & $79 \pm 36$ & $70 \pm 32$ & $65 \pm 31$ & $58 \pm 23$ & .001 & .78 \\
\hline ESVi & $78 \pm 37$ & $38 \pm 14$ & $40 \pm 15$ & $41 \pm 17$ & $44 \pm 21$ & $40 \pm 16$ & $37 \pm 15$ & $32 \pm 13$ & .003 & .57 \\
\hline $\mathrm{EF}$ & $30 \pm 10$ & $38 \pm 9$ & $38 \pm 9$ & $39 \pm 10$ & $42 \pm 10$ & $42 \pm 8$ & $45 \pm 8$ & $45 \pm 7$ & .004 & .03 \\
\hline $\mathrm{E} / \mathrm{A}$ & $0.8 \pm 0.4$ & $1.2 \pm 0.6$ & $1.2 \pm 0.7$ & $1.6 \pm 1.1$ & $1.7 \pm 1.4$ & $0.8 \pm 0.3$ & $0.9 \pm 0.5$ & $0.9 \pm 0.3$ & .55 & .15 \\
\hline DT & $213 \pm 76$ & $150 \pm 55$ & $195 \pm 68$ & $172 \pm 69$ & $184 \pm 63$ & $212 \pm 102$ & $223 \pm 63$ & $224 \pm 32$ & .51 & $<.001$ \\
\hline MAPSE & $10.5 \pm 2$ & $9.1 \pm 2$ & $9.6 \pm 2$ & $10.1 \pm 2$ & $9.1 \pm 2$ & $10.3 \pm 2$ & $11 \pm 3$ & $11 \pm 2$ & .08 & .1 \\
\hline APROT & $0.8 \pm 4.4$ & $5.6 \pm 3.0$ & & & & & $5.4 \pm 3.7$ & & .02 & .81 \\
\hline TORS & $2.8 \pm 4.4$ & $8.7 \pm 3.9$ & & & & & $6.2 \pm 4.7$ & & .02 & .02 \\
\hline
\end{tabular}

Values are presented as mean \pm standard deviation. The number of patients at each control is reported in brackets. The number of patients at each control for apical rotation and $\mathrm{LV}$ torsion is 22 . Linear mixed model $P$ values are reported for preoperative values and time as covariates. $E D V$, End-diastolic volume, $\mathrm{mL} ; E D V i$, end-diastolic volume index, $\mathrm{mL} / \mathrm{m}^{2}$; $E S V$, end-systolic volume, $\mathrm{mL} ; E S V i$, end-systolic volume index, $\mathrm{mL} / \mathrm{m}^{2} ; E F$, ejection fraction, $\%$; DT, E-wave deceleration time, ms; $M A P S E$, mitral annular plane systolic excursion, mm; APROT, apical rotation, degrees; TORS, LV torsion, degrees.

4 years, and 7 years. MAPSE did not differ in the postoperative period. The box-and-whisker plots (Figure 5) of postoperative change of ventricular volumes show 2 different populations before and after surgical reconstruction, with a mean percentage of volume reduction of $45.7 \%$ and $50.9 \%$ of preoperative values (EDVi and ESVi, respectively).

Apical rotation and LV torsion were significantly improved immediately after the operation $(0.8 \pm 4.4$ to $5.6 \pm 3.0$ and $2.8 \pm 4.4$ to $8.7 \pm 3.9$, respectively, $P=.02$ ). This improvement was consistent late after the surgical treatment compared with preoperatively, although torsion showed a decrease during time $(P$ time $=.02)$. The mean increase in apical rotation and LV torsion immediately after the surgical correction was 4.8 (range, 1.5-11.17) and 5.9 (range, 2.69-16.50) degrees, respectively. The difference in $\mathrm{LV}$ torsion of each patient is shown in Figure 6. LV torsion was not worsened by surgery in any of these patients. Postoperative linear correlation between apical rotation and LV torsion $\left(\mathrm{r}^{2}=0.78\right)$ showed dependency of torsion on renewed apical rotation (Figure 7) immediately after surgery as a mechanical and functional result achieved by surgical correction and not by positive remodeling during time.

Polynomial cubic (third-degree) regression curves fit significantly well with the time series analysis of studied parameters: The $\mathrm{R}^{2}$ values for EDVi, ESVi, and EF are

TABLE 2. Significant post hoc comparison (Tukey test) for time intervals

\begin{tabular}{lll}
\hline Variable & \multicolumn{1}{c}{ Comparison } & \multicolumn{1}{r}{} \\
\hline EF & 1 y vs postoperatively & .04 \\
DT & 4 mo vs postoperatively & .05 \\
DT & 4 y vs postoperatively & .002 \\
DT & 7 y vs postoperatively & .04 \\
\hline
\end{tabular}

$E F$, Ejection fraction; $D T$, deceleration time.
$0.77,0.84$, and 0.95 , respectively, and the values for MAPSE, E/A, and DT are $0.60,0.60$, and 0.69 , respectively.

\section{DISCUSSION}

The debate about the need and usefulness of surgical LV reconstruction is far from over, even after the STICH trial results. ${ }^{29}$ The datum that $\mathrm{LV}$ volume reduction obtained in the patients $(19 \%)$ who underwent coronary artery bypass grafting + surgical ventricular reconstruction in the STICH was significantly inferior to the target percentage required in the study protocol (30\%) aroused criticism, ${ }^{30-34}$ confirming the negative outcome reported for large ventricles obtained by different surgical techniques not rebuilding small elliptical volumes. ${ }^{4,5,8,35}$ However, a history of $\mathrm{LV}$ reconstruction shows increasing attention to the respect of normal geometry and structure of the heart, demonstrating that better results are obtained when surgery aims to rebuild an elliptic chamber rather than just a smaller one. The attention to mitral valve function, complete coronary revascularization, and biventricular synchronism added specific improvements to the basic volume reduction.

Because of echocardiographic 2D speckle-tracking analysis, the orientation of myocardial fibers and their physiologic effect on cardiac efficiency can be taken into account in several normal and pathologic conditions. The present study demonstrates that surgically induced renewal of apical rotation and LV torsion can be maintained during time, representing a stable result of this specific reshaping technique. Adding LV torsion to physiologic characteristics of the reconstructed ventricles improves their efficiency, because torsion guarantees obtaining a higher EF with a smaller shortening of myofibers, also reducing the metabolic needs of the myocardium itself. LV torsion increases efficiency of ventricular contraction and may contribute to ensure a steady result during time. Linear correlation between apical rotation and LV torsion showed dependency of torsion on renewed apical rotation, given 

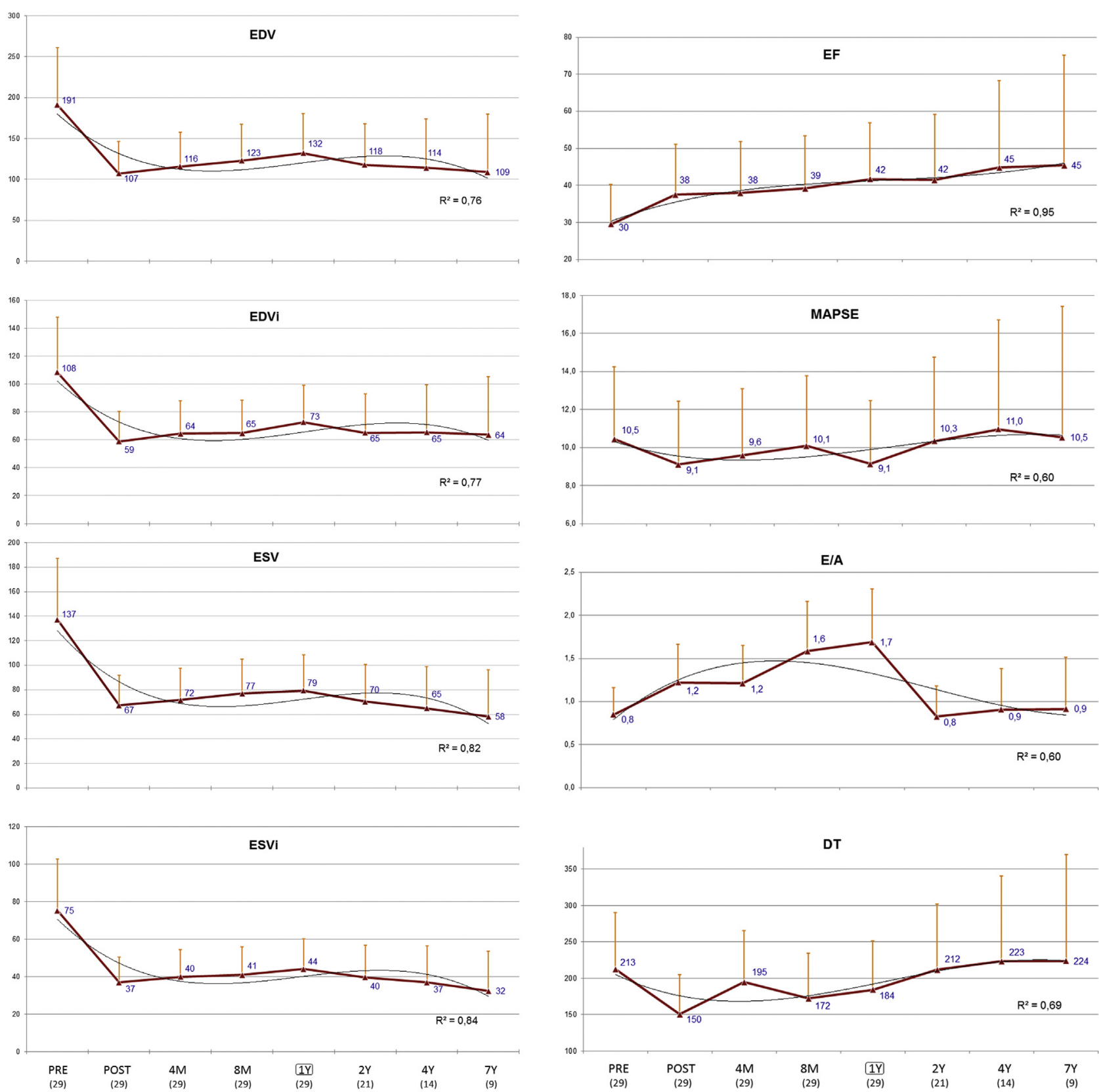

A

B

FIGURE 4. A and B, Time series graphs of the mean values of echocardiographic parameters at each time interval. The 1-year time interval is highlighted (black border). Polynomial cubic (third-degree) regression fitting curves and $\mathrm{R}^{2}$ values are shown for each parameter. The mean value is shown at each time interval, and the number of patients at each control is reported in brackets (x axis). Orange vertical bars indicate $95 \%$ confidence limits. EDV, End-diastolic volume, $\mathrm{mL} ; E D V i$, end-diastolic volume index, $\mathrm{mL} / \mathrm{m}^{2} ; E S V$, end-systolic volume, $\mathrm{mL} ; E S V i$, end-systolic volume index, $\mathrm{mL} / \mathrm{m}^{2} ; E F$, ejection fraction, $\%$; MAPSE, mitral annular plane systolic excursion, $\mathrm{mm}$; $D T$, E-wave deceleration time, ms.

that in this series of patients the postoperative basal rotation was unchanged (no mitral procedures, no perioperative myocardial infarction, preservation of basal segments).

Of note, some ventricles (Figure 7) regain a near-normal apical rotation ( $\sim 11$ degrees) and torsion ( $\sim 14$ degrees). The unexpected renewal (even in a few cases) of a near-normal global function should be considered and studied, given its relevance in the basic science topic of the recovering potential of the myocardium.

We pay specific attention to approach the lateral border of normal myocardium to the patch to rebuild the orientation of anterolateral fibers. Obviously, we cannot rebuild the histologic continuity of fibers, but we can suture gross myocardial fibers' bundles in a way that they can act as in 


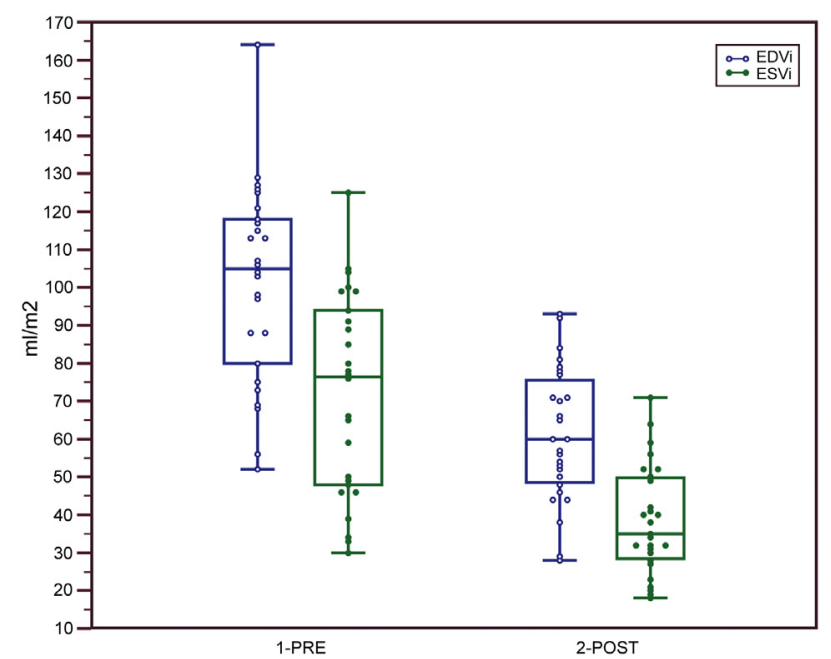

FIGURE 5. Box-and-whiskers plots of EDVi and ESVi preoperatively and postoperatively. The length of the central box contains $50 \%$ of cases (interquartile range); the middle line represents the median; the vertical line extends from the minimum to the maximum value. EDVi, Enddiastolic volume index, $\mathrm{mL} / \mathrm{m}^{2} ; E S V i$, end-systolic volume index, $\mathrm{mL} / \mathrm{m}^{2}$.

the normal setting. Redirected fibers' bundles hinge on the patch in a near-normal orientation, and this may help to renew apical rotation and restore $\mathrm{LV}$ torsion. We observed the renewal of apical rotation just at the end of extracorporeal circulation in the majority of patients, and this was confirmed at the first postoperative echocardiographic control, a few days after the operation. This confirms the direct effect of surgical suture on the reorientation of fibers. This evidence has not been found before in any technique of ventricular reconstruction, whereas some studies dealing with recent or current techniques (Batista, surgical ventricular reconstruction) reported a negative or neutral effect of surgical restoration on LV torsion itself. ${ }^{36,37}$

In our series, the postoperative mean EDVi reduction was $50 \mathrm{~mL} / \mathrm{m}^{2}$ and the mean ESVi reduction was $38 \mathrm{~mL} / \mathrm{m}^{2}$, $45.7 \%$ and $50.9 \%$ of preoperative values, respectively. This reduction remained steady during the postoperative period, with an insignificant volume adjustment in the first year after the operation. Only vital, residual, myocardial tissue was left in the new chamber, and the small short axis of the patch $(<5 \mathrm{~mm}$, including suture) left a small residual akinetic area. LV stroke volume after surgical treatment is ejected by a more efficient, less energywasting and more physiologic ventricular chamber. This halving of ventricular volumes did not affect an easy weaning from extracorporeal circulation or the first phase of postoperative period (eg, extubation time, early mobilization) in any patient, different from previous reports. ${ }^{38}$ Our multifactorial approach to LV reconstruction (elliptical shape with new apex, physiologic volume, redirection of fibers, renewal of torsion) probably helps to obtain and maintain a well-tolerated and steady functional result in the presence of remarkable volume reduction. The concern for reducing ventricular volumes too much is mitigated by these evidences: Great volumes can relapse a negative remodeling, whereas a near-normal volume, joined with other parameters, can guarantee a long-lasting geometric and functional result.

The graph analysis in Figure 4, $A$ and $B$, shows an insignificant but interesting congruous trend of all parameters, centered in the 1-year time interval from the operation: Volumes had a slight increase until this time and then progressively drifted toward a reduction. This variation is 8 to $10 \mathrm{~mL} / \mathrm{m}^{2}$. EF showed a slight and continuous increase

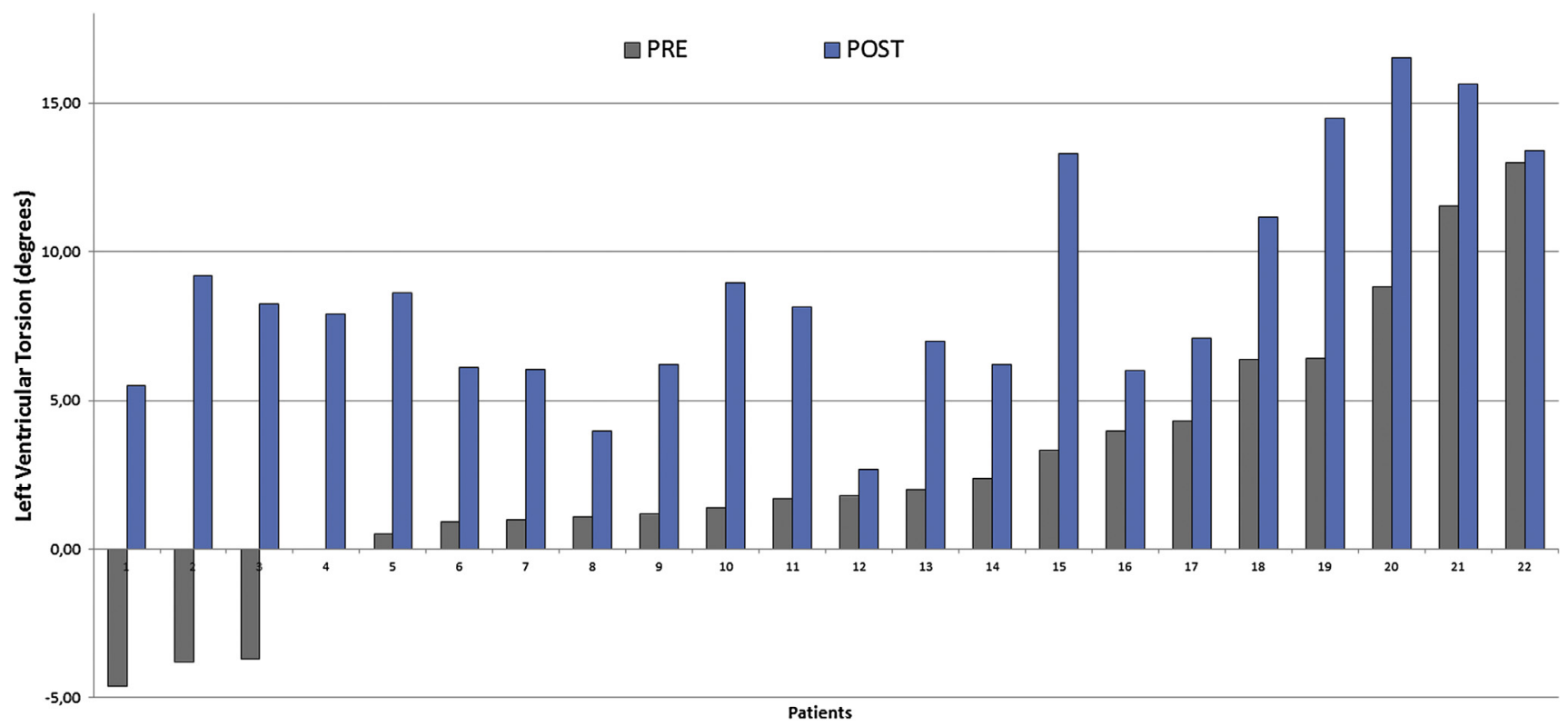

FIGURE 6. Difference between preoperative and postoperative LV torsion of each patient. Patients are sorted for increasing value of preoperative torsion. 


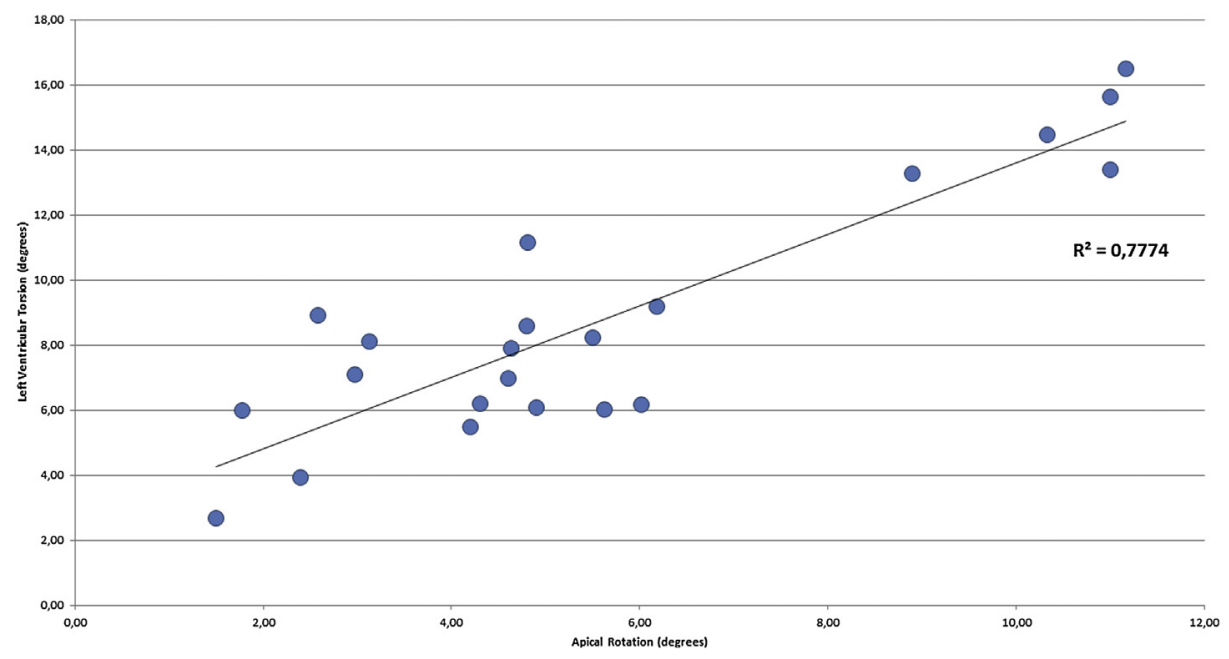

FIGURE 7. Linear correlation between apical rotation and LV torsion in the early postoperative assessment.

during time, significant at 1 year after the operation, reaching a mean late value of $7 \%$ more than postoperative datum. The 1-year time interval could correspond to a physiologic "healing" time of the restored ventricles, and after this time, the functional result could be considered permanent and progressively improving.

This evidence, although not significant, enlightens the biological behavior of ventricles after surgical restoration. This trend during time, if confirmed in larger series, could demonstrate a progressive, timed remodeling. Nevertheless, 1 year could be a too short a period to evaluate these ventricles, and this information can help to conduct (and to judge) clinical studies and echocardiographic controls.

The behavior of diastolic function in our series of patients is concordant with the literature $e^{39-42}$ in regard to the first postoperative year, but it is not significant. This series of patients had an unrestrictive preoperative diastolic pattern and reported a light worsening in diastolic function that was not significant compared with preoperative values. Mitral DT showed a progressive increase during time, with the most significant $P$ value at 1 year after surgery, suggesting that a physiologic LV reconstruction may help to protect diastolic function from permanently changing into a restrictive pattern after the operation, a problem reported as a limitation of this surgical treatment. ${ }^{43,44}$ Other physiologic features obtained with this technique could counterbalance the "stiffness" of the reshaped LV.

After the STICH trial, surgical ventricular reconstruction was confirmed to be an operation that should be performed in highly experienced centers. The lack of significant volume reduction or elliptical shape misguided the STICH results and cast a negative light on the positive effects of this surgery. Surgical conduction of this operation should be standardized to achieve the full spectrum of recoverable physiologic parameters. The renewal of apical rotation and ventricular torsion should be pursued as an adjunctive element of ventricular efficiency, mainly in ventricles that work at a critical level in the Frank-Starling relationship and pressure-volume loop. The described surgical technique reasonably could be indicated for previous anterolateral myocardial infarctions in hearts with conserved or recoverable basal function. The presence of mitral regurgitation is not a contraindication if its mechanism is linked to the previous anterolateral infarction, but can act as a severe limitation on efficacy of this procedure if due to an associated inferior necrosis.

Further studies should be oriented to visualize regional speckle-tracking analysis of myofibers in the neighboring regions of previous myocardial infarction with highresolution ultrasonographic transducer to infer a more precise surgical planning for the rearrangement of fibers. New studies should be performed by experienced centers to properly and effectively conduct this operation to bring it back to its historical and undeniable clinical usefulness.

\section{Study Limitations}

The major limitation of the present study is the small number of patients when compared with large series reported in the literature. ${ }^{3,7,38}$ Because most of the data are highly significant (apical rotation, torsion, volumes, $\mathrm{EF})$ and therefore do not require a power test, we performed a post hoc sensitivity analysis on the postoperative modifications of $\operatorname{ESVi}(P=.57)$ to demonstrate the power of the assumption that these ventricles do not redilate after the operation and do not reach the limit of $50 \mathrm{~mL} / \mathrm{m}^{2}$, which would predict a negative outcome during time. The power of our analysis with a linear mixed model is 0.6 to detect an average 
increase of ESVi to $50 \mathrm{~mL} / \mathrm{m}^{2}$ within 24 months after surgery. The sample needed to obtain a study power of 0.8 consists of approximately twice the actual number of patients. Complete assessment of diastolic function also should include E/E' values, which are not reported in the present study. Nevertheless, this is an example of long-lasting follow-up study of selected patients suitable for this surgical procedure that achieved significant, original results potentially affecting basic science and clinical outcomes. ${ }^{45}$ It is clear that restoration of LV torsion is based on a sort of mind-guided reset of true anatomic disposition of myocardial fibers in the heart of mammals, but currently cannot be planned on an imaging-based technique. This could account for the actual disparity in results and the poor predictability. Further studies with multicenter expertise participation could overcome these current limitations.

\section{CONCLUSIONS}

Surgical conduction of left ventricular reconstruction should be standardized to achieve the full spectrum of recoverable physiologic parameters. The renewal of ventricular torsion should be pursued as an adjunctive element of ventricular efficiency, mainly in ventricles that work at a critical level in the Frank-Starling relationship and pressure-volume loop.

\section{Conflict of Interest Statement}

Authors have nothing to disclose with regard to commercial support.

\section{References}

1. Cooley DA, Collins HA, Morris GC Jr, Chapman DW. Ventricular aneurysm after myocardial infarction; surgical excision with use of temporary cardiopulmonary bypass. J Am Med Assoc. 1958;167:557-60.

2. Jones RH, Velazquez EJ, Michler RE, Sopko G, Oh JK, O'Connor CM, et al. Coronary bypass surgery with or without surgical ventricular reconstruction. N Engl J Med. 2009;360:1705-17.

3. Dor V, Kreitmann P, Jourdan J. Interest of 'physiological' closure (circumferential plasty on contractile areas) of left ventricle after resection and endocardectomy for aneurysm or akinetic zone: comparison with classical technique of about 209 left ventricular resections. J Cardiovasc Surg. 1985;26:73.

4. Bolooki H, DeMarchena E, Mallon SM, Katariya K, Barron M, Bolooki HM, et al. Factors affecting late survival after surgical remodeling of left ventricular aneurysms. J Thorac Cardiovasc Surg. 2003;126:374-83.

5. Kono T, Sabbah HN, Stein PD, Brymer JF, Khaja F. Left ventricular shape as a determinant of functional mitral regurgitation in patients with severe heart failure secondary to either coronary artery disease or idiopathic dilated cardiomyopathy. Am J Cardiol. 1991;68:355-9.

6. Di Mauro M, Iacò AL, Bencivenga S, Clemente D, Marcon S, Asif M, et al. Left ventricular surgical remodelling: is it a matter of shape or volume? Eur J Cardiothorac Surg. 2015;47:473-9.

7. Buckberg G, Athanasuleas C, Conte J. Surgical ventricular restoration for the treatment of heart failure. Nat Rev Cardiol. 2012;9:703-16.

8. Adhyapak SM, Parachuri VR. Architecture of the left ventricle: insights for optimal surgical ventricular restoration. Heart Fail Rev. 2010;15:73-83.

9. Shaw SM, Fox DJ, Williams SG. The development of left ventricular torsion and its clinical relevance. Int J Cardiol. 2008;130:319-25.
10. Rüssel IK, Götte MJ, Bronzwaer JG, Knaapen P, Paulus WJ, van Rossum AC Left ventricular torsion: an expanding role in the analysis of myocardial dysfunction. JACC Cardiovasc Imaging. 2009;2:648-55.

11. Sengupta PP, Khandheria BK, Narula J. Twist and untwist mechanics of the left ventricle. Heart Fail Clin. 2008;4:315-24.

12. Buckberg GD, Hoffman JI, Coghlan HC, Nanda NC. Ventricular structurefunction relations in health and disease: Part I. The normal heart. Eur J Cardiothorac Surg. 2015;47:587-601.

13. Buckberg GD, Hoffman JI, Coghlan HC, Nanda NC. Ventricular structurefunction relations in health and disease: part II. Clinical considerations. Eur J Cardiothorac Surg. 2015;47:778-87.

14. Buckberg G. Outcomes of left ventricular reconstruction when established parameters are followed, and subsequent questions. Eur J Cardiothorac Surg. 2012;42:393-7.

15. Sengupta PP, Korinek J, Belohlavek M, Narula J, Vannan MA, Jahangir A, et al. Left ventricular structure and function: basic science for cardiac imaging. J Am Coll Cardiol. 2006;48:1988-2001.

16. Cirillo M, Villa E, Troise G. Improvement of left ventricular function after modified surgical ventricular restoration: good, better, best. Heart Surg Forum. 2008; 11:E266-9.

17. Cirillo M, Campana M, Brunelli F, Tomba MD, Mhagna Z, Messina A, et al. "Let's twist again": surgically induced renewal of left ventricular torsion in ischemic cardiomyopathy. J Cardiovasc Med (Hagerstown). 2010;11:34-9.

18. Cirillo M, Arpesella G. Rewind the heart: a novel technique to reset heart fibers' orientation in surgery for ischemic cardiomyopathy. Med Hypotheses. 2008;70: 848-54.

19. Cirillo M. A new surgical ventricular restoration technique to reset residual myocardium's fiber orientation: the "KISS" procedure. Ann Surg Innov Res. 2009;3: 6.

20. Rosberg A, Gharib M, Kheradvar A. Effect of fiber geometry on pulsatile pumping and energy expenditure. Bull Math Biol. 2009;71:1580-98.

21. Esch BT, Warburton DE. Left ventricular torsion and recoil: implications for ex ercise performance and cardiovascular disease. J Appl Physiol (1985). 2009;106: $362-9$.

22. Matos J, Kronzon I, Panagopoulos G, Perk G. Mitral annular plane systolic excursion as a surrogate for left ventricular ejection fraction. J Am Soc Echocardiogr. 2012;25:969-74.

23. Lang RM, Badano LP, Mor-Avi V, Afilalo J, Armstrong A, Ernande L, et al. Recommendations for cardiac chamber quantification by echocardiography in adults: an update from the American Society of Echocardiography and the European Association of Cardiovascular Imaging. J Am Soc Echocardiogr. 2015;28:1-39.

24. Porter TR, Shillcutt SK, Adams MS, Desjardins G, Glas KE, Olson JJ, et al. Guidelines for the use of echocardiography as a monitor for therapeutic intervention in adults: a report from the American Society of Echocardiography. J Am Soc Echocardiogr. 2015;28:40-56.

25. McDonald JH. Handbook of Biological Statistics. 3rd ed. University of Delaware. Baltimore, MD: Sparky House Publishing; 2014.

26. Isomura $\mathrm{T}$, Horii $\mathrm{T}$, Suma H, Buckberg GD, RESTORE Group. Septal anterior ventricular exclusion operation (Pacopexy) for ischemic dilated cardiomyopathy: treat form not disease. Eur J Cardiothorac Surg. 2006;29(Suppl 1):S245-50.

27. Chen J, Song S, Liu W, McLean M, Allen JS, Tan J, et al. Remodeling of cardiac fiber structure after infarction in rats quantified with diffusion tensor MRI. Am J Physiol Heart Circ Physiol. 2003;285:H946-54.

28. Peyrat JM, Sermesant M, Pennec X, Delingette H, Xu C, McVeigh ER, et al. A computational framework for the statistical analysis of cardiac diffusion tensors: application to a small database of canine hearts. IEEE Trans Med Imaging. 2007; 26:111500-14.

29. Buckberg G, Athanasuleas CL, Wechsler AS, Beyersdorf F, Conte JV, Strobeck JE. The STICH trial unravelled. Eur J Heart Fail. 2010;12: 1024-7.

30. Isomura T, Hoshino J, Fukada Y, Kitamura A, Katahira S, Kondo T, et al. Volume reduction rate by surgical ventricular restoration determines late outcome in ischaemic cardiomyopathy. Eur J Heart Fail. 2011;13:423-31.

31. Suma H, Anyanwu AC. Current status of surgical ventricular restoration for ischemic cardiomyopathy. Semin Thorac Cardiovasc Surg. 2012;24:294-301.

32. Buckberg GD, Athanasuleas CL. The STICH trial: misguided conclusions. J Thorac Cardiovasc Surg. 2009;138:1060-4.

33. Athanasuleas CL, Buckberg GD. The STICH trial data: keep it simple. J Thorac Cardiovasc Surg. 2015;149:1682-3. 
34. Michler RE, Rouleau JL, Al-Khalidi HR, Bonow RO, Pellikka PA, Pohost GM, et al. Insights from the STICH trial: change in left ventricular size after coronary artery bypass grafting with and without surgical ventricular reconstruction. $J$ Thorac Cardiovasc Surg. 2013;146:1139-45.

35. Raman J, Dixit A, Bolotin G, Jeevanandam V. Failure modes of left ventricular reconstruction or the Dor procedure: a multi-institutional perspective. Eur J Cardiothorac Surg. 2006;30:347-52.

36. Setser RM, Kasper JM, Lieber ML, Starling RC, McCarthy PM, White RD. Persistent abnormal left ventricular systolic torsion in dilated cardiomyopathy after partial left ventriculectomy. J Thorac Cardiovasc Surg. 2003;126:48-55.

37. Setser RM, Smedira NG, Lieber ML, Sabo ED, White RD. Left ventricular torsional mechanics after left ventricular reconstruction surgery for ischemic cardiomyopathy. J Thorac Cardiovasc Surg. 2007;134:888-96.

38. Menicanti L, Castelvecchio S, Ranucci M, Frigiola A, Santambrogio C, De Vincentiis C, et al. Surgical therapy for ischemic heart failure: single-center experience with surgical anterior ventricular restoration. J Thorac Cardiovasc Surg. 2007;134:433-41.

39. Bové T, Van Belleghem Y, Vandenplas G, Caes F, François K, De Backer J, et al. Short-term systolic and diastolic ventricular performance after surgical ventricular restoration for dilated ischemic cardiomyopathy. Eur J Cardiothorac Surg. 2009;35:995-1003.
40. Marui A, Nishina T, Saji Y, Yamazaki K, Shimamoto T, Ikeda T, et al. Significance of left ventricular diastolic function on outcomes after surgical ventricular restoration. Ann Thorac Surg. 2010;89:1524-31.

41. Di Donato M, Menicanti L, Ranucci M, Castelvecchio S, de Vincentiis C, Salvia J, et al. Effects of surgical ventricular reconstruction on diastolic function at midterm follow-up. J Thorac Cardiovasc Surg. 2010;140:285-91.

42. Castelvecchio S, Menicanti L, Donato MD. Surgical ventricular restoration to reverse left ventricular remodeling. Curr Cardiol Rev. 2010;6: $15-23$.

43. Dickstein ML, Spotnitz HM, Rose EA, Burkhoff D. Heart reduction surgery: an analysis of the impact on cardiac function. J Thorac Cardiovasc Surg. 1997;113: $1032-40$.

44. Ratcliffe MB, Wallace AW, Salahieh A, Hong J, Ruch S, Hall TS. Ventricular volume, chamber stiffness, and function after anteroapical aneurysm plication in the sheep. J Thorac Cardiovasc Surg. 2000;119:115-24.

45. Murthy SC, Blackstone EH. Research based on big data: the good, the bad, and the ugly. J Thorac Cardiovasc Surg. 2016;151:629-30.

Key Words: left ventricular torsion, surgical ventricular reconstruction, ischemic cardiomyopathy

Readers who found these articles interesting may also like to read the following papers found in recent and future issues of our sister publications, Seminars in Thoracic and Cardiovascular Surgery and Operative Techniques in Thoracic and Cardiovascular Surgery!

\section{Acquired: Coronary Artery Disease}

Original Submissions: Micromorphology of Skeletonized and Pedicled Internal Thoracic and Radial Arteries. Sergey Mamchur. Semin Thorac Cardiovasc Surg 2015; Summer; 27(2):115-120.

Editorial Commentary: Harvesting Arterial Grafts: Barebones or More. Faisal G. Bakaeen. Semin Thorac Cardiovasc Surg 2015; 27(2):121-122. 